\title{
Novel Morphology in Ring-Banded Spherulites from Single-Phase Mixtures of Poly(E-caprolactone) with Poly(styrene-co-acrylonitrile)
}

\author{
Zhigang $\mathrm{WANG}_{\mathrm{AN}}{ }^{\dagger}$ Lijia AN, Bingzheng JIANG, \\ Xuehui $\mathrm{WANG}_{\mathrm{AN}}{ }^{*}$ and Hanying $\mathrm{ZHAO}^{* *}$ \\ Polymer Physics Laboratory, Changchun Institute of Applied Chemistry, Chinese Academy of Sciences, \\ Changchun 130022, People's Republic of China \\ * Department of Chemical Engineering, Jilin Institute of Technology Changchun 130012, \\ People's Republic of China \\ ** Institute of Macromolecular Science, Fudan University, Shanghai 200433, People's Republic of China
}

(Received July 11, 1997)

\begin{abstract}
Novel morphology of ring-banded spherulites in the surface of poly( $\varepsilon$-caprolactone)/poly(styrene-coacrylonitrile) (PCL/SAN) blends was discovered and studied by SEM and TEM. The ring-banded spherulites separate into those exhibiting a very dark contrast, of relatively regular bundles of lamellae and others appearing with a much brighter intensity, of a coarse and irregular aggregates of lamellae. The origin of the novel morphology is not due to different crystalline structures as in the case of isotactic polypropylene because only one crystal structure exists in PCL/SAN blends. The formation may reflect whether spherulites in PCL/SAN blends are nucleated at the bottom surface or at the top (free) surface.

KEY WORDS Poly(E-caprolactone) / Poly(styrene-co-acrylonitrile) / Ring-Banded Spherulite / Morphology /
\end{abstract}

Polymers undergoing phase transformation show a wide variety of microstructures. The most common growth is termed "spherulitic." This form consists of radial arrays of lamellar crystals. Poly( $\varepsilon$-caprolactone) (PCL) is miscible on a molecular level with poly(styreneco-acrylonitrile) (SAN) when copolymer contains from 8 to $28 \mathrm{wt} \%$ acrylonitrile. ${ }^{1}$ When below the melting temperature $\left(T_{\mathrm{m}}\right)$ of PCL, PCL lamellae grow (crystallization), and between them, a homogeneous mixture of amorphous PCL and SAN should remain. The crystallization behavior of PCL is strongly influenced when amorphous SAN is present. This leads to ring-banded spherulites. $^{2-5}$ However, to our knowledge, it is not enough, up to now, to investigate the morphology of ring-banded spherulites formed in PCL/SAN blends or the mixtures of PCL with other polymers by electron microscope. $^{2-12}$ This paper studies novel spherulitic morphology on the surface of ring-banded spherulites generated in PCL/SAN blends. A possible formation mechanism of two types of ring-banded spherulites is discussed.

\section{EXPERIMENTAL}

PCL was purchased from Polysciences Inc. (U.S.A.). $M_{w}$ and $M_{n}$ determined by gel permeation chromatography (GPC) are 22000 and 11300, respectively. The melting temperature of PCL is about $60^{\circ} \mathrm{C}$ from differential scanning calorometry (DSC) measurement. SAN with $25 \mathrm{wt} \%$ acrylonitrile (AN) content was supplied by Polysciences Inc. The $M_{w}$ and $M_{n}$ are 197000 and 106000 by GPC, respectively. $T_{\mathrm{g}}$ of SAN is about $105^{\circ} \mathrm{C}$ measured by DSC. Samples of PCL and PCL/SAN (90/10) blends were prepared by mixing in $\mathrm{CH}_{2} \mathrm{Cl}_{2}$. A dilute solution $(5 \% \mathrm{wt} / \mathrm{wt})$ was stirred continuously for $24 \mathrm{~h}$ at $25^{\circ} \mathrm{C}$. The thin films were cast on a clean cover glass

To whom correspondence should be addressed. and held in a vacuum oven at $40^{\circ} \mathrm{C}$ for three days. The isothermal crystallization of PCL and PCL/SAN blends was performed on two home-made optical microscope hot stages, in which temperature was controlled within $\pm 0.1^{\circ} \mathrm{C}$. The films with a free surface upwards were first melted on one hot stage at $80^{\circ} \mathrm{C}$ for $5 \mathrm{~h}$, then rapidly transported to another hot stage controlled at crystallization temperature $\left(T_{\mathrm{c}}\right)$ of $35^{\circ} \mathrm{C}$ and maintained for $24 \mathrm{~h}$.

After crystallization, the films without surface treatment were sputter-coated with gold directly and examined in the JEOL JXA-840 SEM apparatus using an accelerating voltage of $15 \mathrm{kV}$. The surfaces of the films were also investigated by transmission electron microscope (TEM). The specimens were replicated, after shadowing first with a very thin platinum/palladium $(\mathrm{Pt} / \mathrm{Pd})$ layer at an angle of $\sim 30^{\circ}$. Thicker and vertical backing of carbon followed. The composite film of $\mathrm{Pt} / \mathrm{Pd}-\mathrm{C}$ layer plus shadowed crystals can be pick up quite easily using a fresh razor blade. The composite layer was placed in distilled water in a Petti dish, and after several drops of $\mathrm{CH}_{2} \mathrm{Cl}_{2}$ were used to dissolve the PCL/SAN blends $(\sim 5 \mathrm{~h})$, the replica was mounted on electron microscope grids in the conventional way for TEM. TEM micrographs were obtained by performing a JEM-2010 microscope with an accelerator voltage of $200 \mathrm{kV}$.

Other complementary structural techniques such as DSC and Wide angle X-ray diffraction (WAXD) were also used. The samples of PCL and PCL/SAN blends having crystallized for $24 \mathrm{~h}$ at $35^{\circ} \mathrm{C}$ were collected using a razor blade from the cover glasses. About $10 \mathrm{mg}$ samples were measured by DSC, using a Perkin-Elmer 7 Series Thermal Analysis System operated at a heating rate of $10^{\circ} \mathrm{C} \mathrm{min}^{-1}$ under a nitrogen atmosphere. WAXD was carried out for the powder samples of PCL and PCL/SAN blends, collected as above, in a PW1700 automatic diffractometer (Philips Co., Holland) with a 


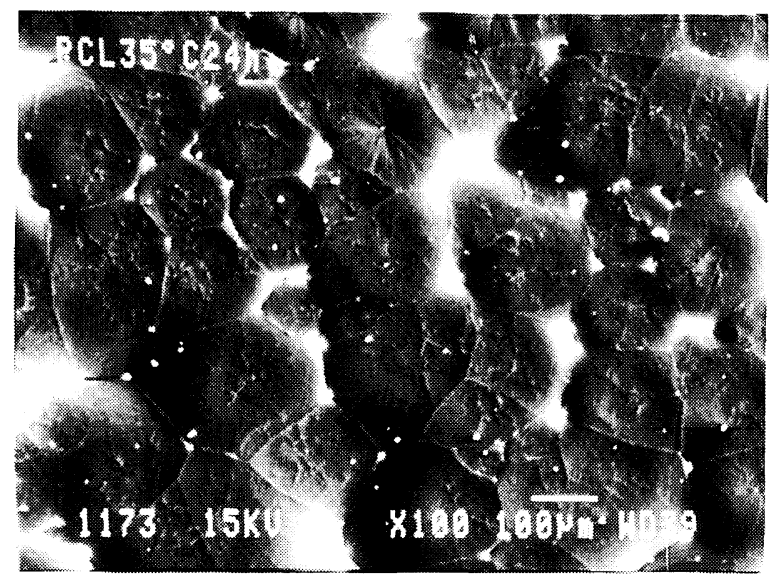

(a)

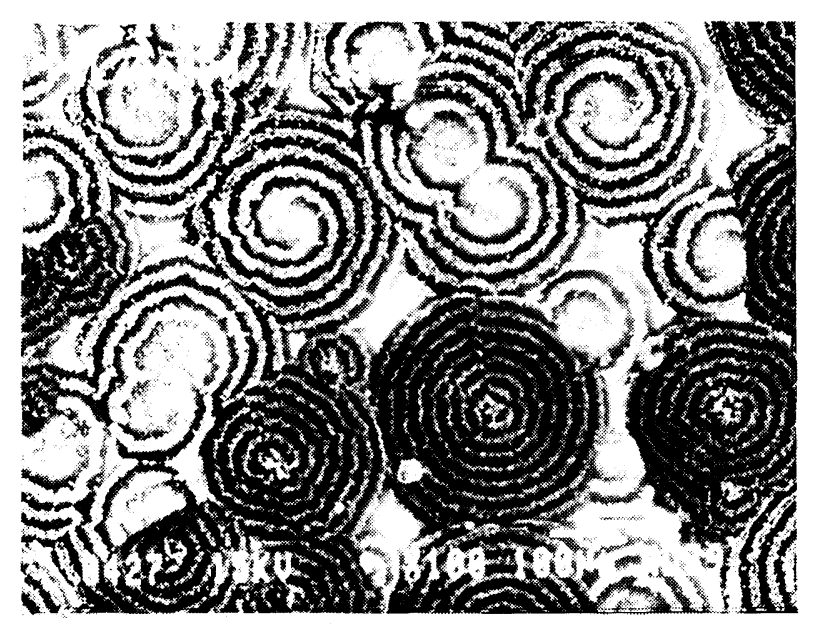

(b)

Figure 1. SEM micrographs of PCL (a) and PCL/SAN $(90 / 10)$ blends (b) crystallized at $35^{\circ} \mathrm{C}$ for $24 \mathrm{~h}$, respectively. (a) and (b) have the same scale.

nickel-filter and $\mathrm{Cu}-K_{\alpha}$ radiation at a scanning rate of $0.3^{\circ} \mathrm{min}^{-1}$ in an angle range from $5^{\circ}$ to $45^{\circ}$.

\section{RESULTS AND DISCUSSION}

The micrographs in Figures $1 \mathrm{a}$ and $1 \mathrm{~b}$ show the surfaces of PCL and PCL/SAN (90/10) blends crystallized at $35^{\circ} \mathrm{C}$ for $24 \mathrm{~h}$, respectively. The spherulitic structures are quite different between pure PCL and its blends with SAN. In Figure la, the spherulites are normal, with an average diameter of $\sim 150 \mu \mathrm{m}$. However, Figure $1 b$ is very different. Ring-banded spherulites are seen. The ring-banded spherulites on the surface of PCL/SAN blends clearly separate into those exhibiting dark contrast, while the other with much brighter intensity. What is the origin of the novel morphology? It is known that in SEM, the brightness of the image is related to the number of electrons scattered from the sample surface towards the detector. For an ideally flat surface, the secondary electron coefficient (i.e., the yield of secondary electrons) is given by $\delta=\delta_{0} \sec \left(\theta_{\mathrm{s}}\right)$, where $\theta_{\mathrm{s}}$ is the specimen tilt angle. ${ }^{13}$ If the surface is normal to the incident beam, most secondary electrons are scattered within the sample and only a few escape from the sample. Brightness is therefore very low. In contrast, at a small incidence angle, the number of secondary electrons scattered from the surface increases and the brightness of the image is therefore much higher. So, it is thought that the contrast difference for these two ring-banded spherulites may be caused by different substructures; one substructure having a relatively less fluctuation surface, which will release less secondary electrons to the detector to yield dark images and the other having a 'wavy' surface, which will release more secondary electrons to the detector to yield bright image.

To study the two novel surface morphologies in the ring-banded spherulites, the replica from surface was observed by TEM. Figure 2 shows TEM micrographs of the replicated surface. Figure $2 \mathrm{a}$ affords the picture of parts of two types of ring-banded spherulites with a low magnification. The spherulite on up side in Figure 2a corresponds to the dark spherulites in SEM and that on low side corresponds to the bright spherulites in SEM. Figures $2 b$ and $2 c$ reveal the differences more fully at higher magnification. The dark spherulites in SEM show relatively regular bundles of lamellae while the bright spherulites in SEM possess a coarse and irregular aggregates of lamellae, rounded or faceted.

To our knowledge, dark and bright spherulites were first observed SEM by Aboulfaraj et al., using an isotactic polypropylene sample. ${ }^{14,15}$ The etched surfaces of meltcrystallized bulk polypropylene were observed by SEM, which revealed two populations of the spherulites with different contrast associated with the crystalline structures. The $\alpha$-spherulites are dark while the $\beta$-ones very bright. This contrast is discussed in terms of the topology of the etched surface. Each spherulite in isotactic polypropylene has ever been characterized by optical microscopy and TEM by Norton and Keller. ${ }^{16}$ In fact, the results from SEM and TEM in their papers are in agreement. In the case of PCL, however, only one crystal structure, orthorhombic, was reported. ${ }^{17}$ Therefore, the two populations of the spherulites should not correspond to the $\alpha$ - or $\beta$-spherulites as in the case of isotactic polypropylene. For proving this viewpoint, two complementary structural techniques including DSC and WAXD were used. DSC thermograms of PCL and PCL/SAN blends from the glass cover are displayed in Figure 3. Their curves are similar and both display a single endotherm at $\sim 60^{\circ} \mathrm{C}$, which is clearly related to the melting point of PCL crystals. Because of the agreement of DSC curves of PCL and PCL/SAN blend, the $\alpha$ - and $\beta$-forms can not be found in PCL/SAN blends, as is different from that in ref 8 , where the DSC thermograms change when bright and dark spherulites co-exist. The WAXD patterns of PCL and PCL/SAN blends are displayed in Figure 4. There is a rather broad hump at the diffraction angle $2 \theta \approx 20^{\circ}$, which is characteristic of the amorphous component. Sharp peaks at $2 \theta \approx 21.4$ and $23.7^{\circ}$ are superimposed on the former, due to diffraction by the crystalline lamellae. The diffraction peaks can be indexed to (110) and (200), respectively. As amorphous component SAN is added, the crystalline reflection peaks become shorter and broader. However, the positions of the peak maxima are almost independent of composition. It is obvious that the WAXD patterns reveal no trace of co-exist of the $\alpha$ - and $\beta$-forms in PCL/SAN blends. ${ }^{14,16}$

The dark and bright spherulites in PCL/SAN blends 


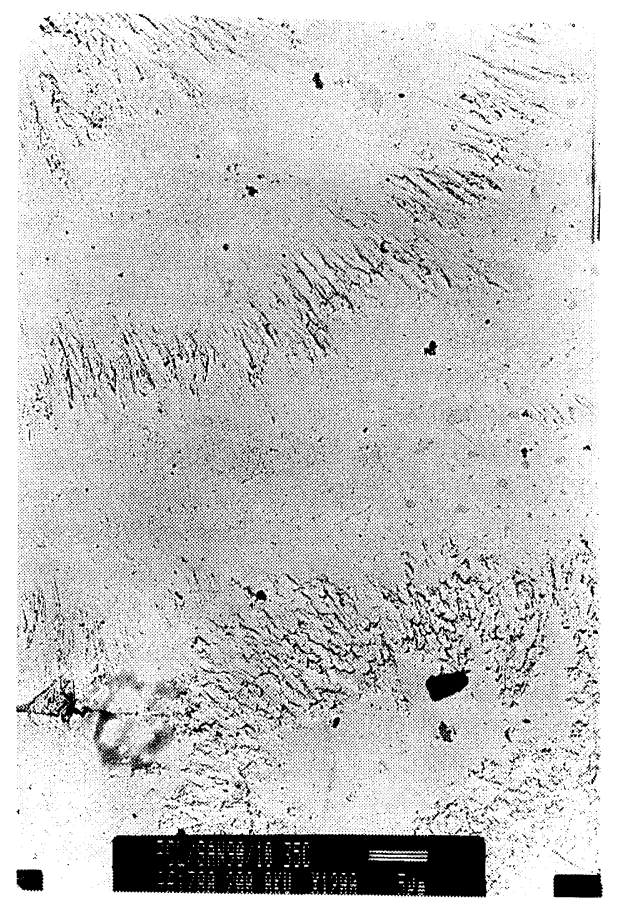

(a)

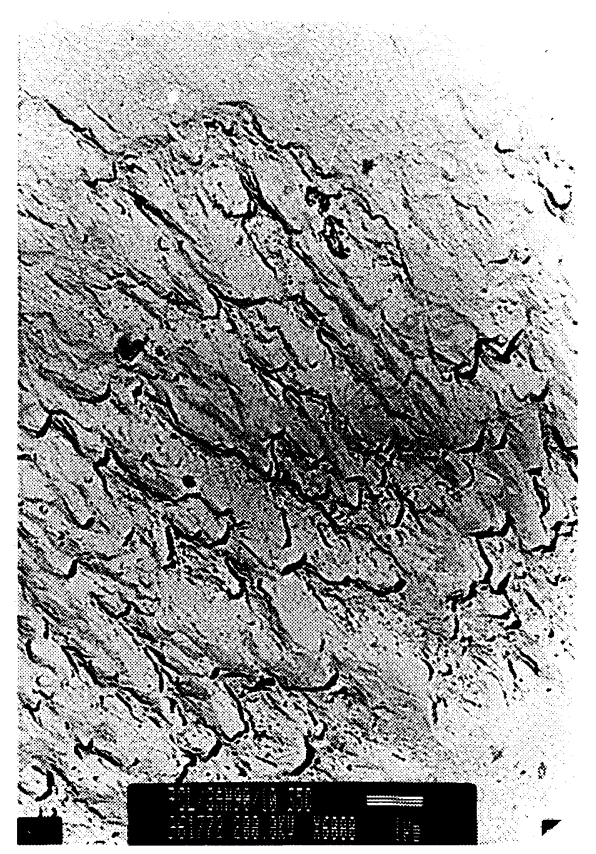

(b)

have different properties and formation mechanism from these in isotactic polypropylene. First, there are no coexitting $\alpha$ - and $\beta$-spherulites in PCL/SAN blends. Secondly, the dark and bright spherulites in isotactic polypropylene are obtained from the etched surface, which is distinct to the free surface in PCL/SAN blends. What is the formation mechanism for these two types of spherulites in the blends? It is considered that the mechanism may be connected with where each spherulite was nucleated during crystallization process of PCL/SAN blends. That is the formation of two types of spherulites may reflect whether a spherulite was nucleated at the bottom surface or at the top (free) surface. In the former case, the lamellar tips would be coming upward, which brings about lots of edges and roughness, while in the

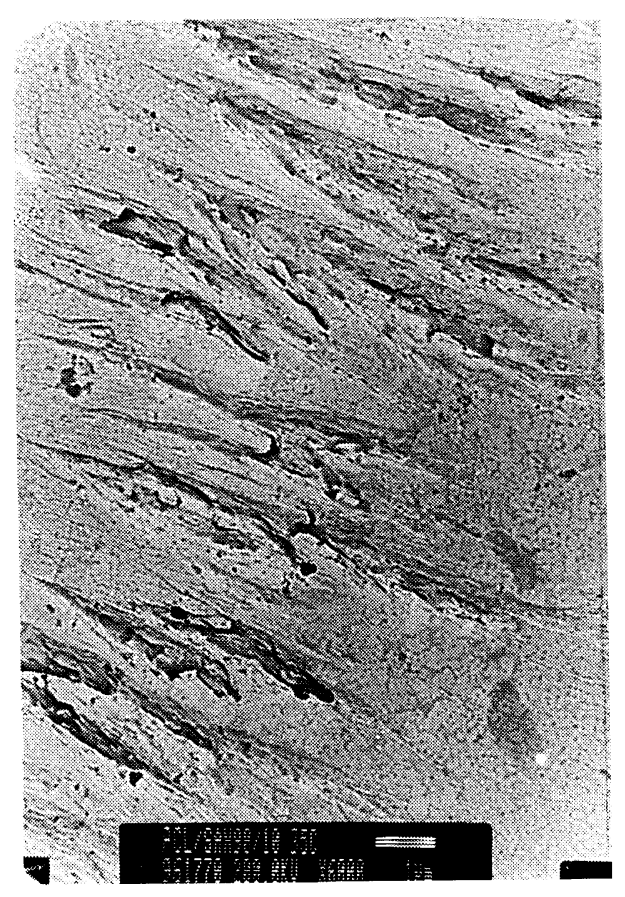

(c)

Figure 2. TEM micrographs of replicas from the surface of PCL/SAN $(90 / 10)$ blends crystallized at $35^{\circ} \mathrm{C}$ for $24 \mathrm{~h}$. (a) lower resolution showing the two spherulites; (b) upper spherulite in (a); (c) lower spherulite in (a) with higher resolution showing each spherulite.

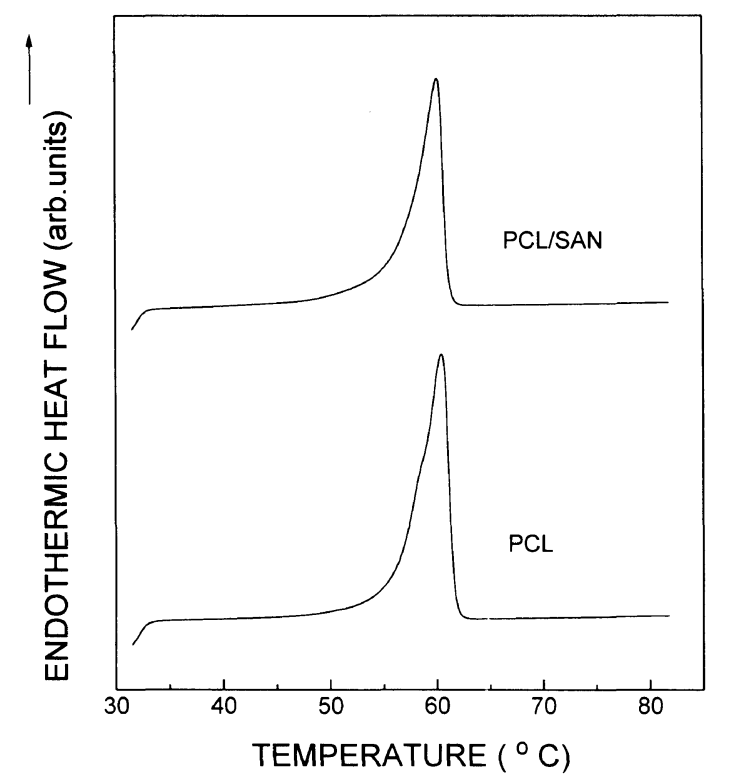

Figure 3. DSC scans of PCL and PCL/SAN (90/10) blends crystallized at $35^{\circ} \mathrm{C}$ for $24 \mathrm{~h}$ at a heating rate of $10^{\circ} \mathrm{C} \mathrm{min}^{-1}$.

latter case the lamellae would be parallel to the surface and the tips would be pointing downwards, which brings about fairly smooth surface. In PCL/SAN blends, the addition of SAN changes significantly spherulitic morphology as can seen from Figure 1. The formation of ring-banded spherulites has a inherent relationship with the mobility of the segments in mixtures and the glass transition temperature of the mixture has predominant influence on crystallization kinetics of PCL/SAN mixtures. ${ }^{18,19}$ Specific interactions between the components of PCL and SAN in the mixtures alter the mo- 


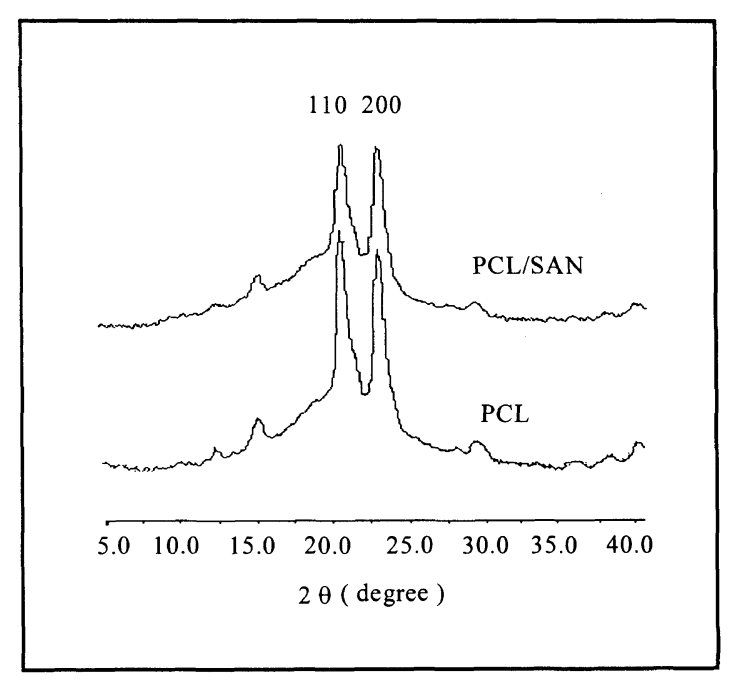

Figure 4. WAXD powder patterns of PCL and PCL/SAN $(90 / 10)$ blends crystallized at $35^{\circ} \mathrm{C}$ for $24 \mathrm{~h}$.

bility of both crystallizable and noncrystallizable components significantly through the amorphous component with higher $T_{\mathrm{g}}$, SAN. The addition of SAN the sample crystallizes somewhat more slowly. ${ }^{19}$ Therefore SAN in the blends can surely influence nucleation by changing the overall mobility of the segments in the mixture, resulting in two types of spherulites.

\section{CONCLUSIONS}

Novel morphology of ring-banded spherulites on the surface of PCL/SAN blends was studied by SEM and TEM. The ring-banded spherulites are either relatively regular bundles of lamellae on those with a much brighter intensity, of coarse and irregular aggregates of lamellae. The origin of the novel morphology is not due to different crystalline structures, such as $\alpha$ - or $\beta$-spherulites as in the case of isotactic polypropylene. The differences between the two spherulites may reflect whether spherulites are nucleated at the bottom or top (free) surface.

Acknowledgments. We are in debt to the financial support by the National Natural Science Foundation of China and 'National Basic Research Project-Macromolecular Condensed State' Foundation of China.

\section{REFERENCES}

1. S. C. Chiu and T. G. Smith, J. Appl. Polym. Sci., 29, 1797 (1984).

2. P. Svoboda, J. Kressler, T. Chiba, T. Inoue, and H. W. Kammer, Macromolecules, 27, 1154 (1994).

3. J. Kressler, P. Svoboda, and T. Inoue, Polymer, 34, 3225 (1993).

4. C. Kunmerlove and H. W. Kammer, Polym. Networks Blends, 5, 131 (1995).

5. K. Schulze, J. Kressler, and H. W. Kammer, Polymer, 34, 3704 (1993).

6. W. Li, R. J. Yan, and B. Z. Jiang, Polymer, 33, 889 (1992).

7. J. Runt and P. B. Rim, Macromolecules, 15, 1018 (1982).

8. Y. W. Cheung, R. S. Stein, G. D. Wignall, and H. E. Yang, Macromolecules, 26, 5365 (1993).

9. Y. W. Cheung, R. S. Stein, B. Chu, and G. Wu, Macromolecules, 27, 3589 (1994).

10. Y. Li and B.-J. Jungnickel, Polymer, 34, 9 (1993).

11. S. Nojima, Y. Takahashi, and T. Ashida, Polymer, 36, 2853 (1995).

12. H. Tanaka and T. Nishi, Phy. Rev. A, 39, 783 (1989).

13. P. J. Goodhew and F. J. Humphreys, "Electron Microscopy and Analysis," Taylor and Francis, London, 1988.

14. M. Aboulfaraj, B. Ulrich, A. Dahoun, and C. G'Sell, Polymer, 34, 4817 (1993).

15. M. Aboulfaraj, C. G'Sell, B. Ulrich, and A. Dahoun, Polymer, 36, 731 (1995).

16. D. R. Norton and A. Keller, Polymer, 26, 704 (1985).

17. H. Hu and D. L. Dorset, Macromolecules, 23, 4604 (1990).

18. Z. G. Wang, X. H. Wamg, D. H. Yu, and B. Z. Jiang, Polymer, in press.

19. Z. G. Wang and B. Z. Jiang, Macromolecules, in press. 